\title{
Cultura Cultura
}

Revista de Historia e Teria das ldeais $\quad$ Revista de História e Teoria das Ideias

Vol. 26| 2009

0 Tempo das Revistas

\section{O valor das ideias}

\section{Luís Andrade}

\section{(Q) OpenEdition \\ Journals}

Edição electrónica

URL: http://journals.openedition.org/cultura/739

DOI: 10.4000/cultura.739

ISSN: 2183-2021

\section{Editora}

Centro de História da Cultura

\section{Edição impressa}

Data de publição: 1 Junho 2009

Paginação: 9-13

ISSN: 0870-4546

\section{Refêrencia eletrónica}

Luís Andrade, «O valor das ideias », Cultura [Online], Vol. 26 | 2009, posto online no dia 16 setembro 2013, consultado a 20 abril 2019. URL : http://journals.openedition.org/cultura/739 ; DOI : 10.4000/ cultura.739 


\title{
O valor das ideias
}

\author{
Luís Andrade*
}

Entre os traços mais salientes da cultura e da política contemporâneas, encontra-se o mérito conferido às novas doutrinas, não só no âmbito da interpretação do mundo e da vida, mas também, e fundamentalmente, nos domínios da transformação das sociedades e do quotidiano.

Acreditava-se que as ideias faziam a história, que o pensamento, ao assomar à condição de consciência efectiva da natureza e da invenção comuns, elucidava os tempos e se metamorfoseava em programa da acção pertinente.

As concepções novas encarregaram-se, assim, de projectar a seu modo o percurso colectivo, desde logo a elevação às novas eras perspectivadas pelas muitas revoluções políticas, estéticas, tecnológicas, que quebraram definitivamente a circularidade ancestral da tradição, transformaram as sociedades segundo um ritmo insuspeito e promoveram o cultivo da modernidade.

Emancipação racional, cultura e política passaram a caminhar a par:a ordem antiga deu lugar a comunidades políticas constituídas de acordo com ideários e contratos sociais originais; as organizações partidárias, resultantes da vida parlamentar, encontraram justificação em representações explícitas do itinerário para a cidade almejada; os imaginários conferiram, nas letras e nas artes, expressão simbólica à luz e ao calor das novas convicções.

Em simultâneo, o número dos que acompanharam e participaram nos acontecimentos políticos e culturais correntes superou, progressivamente, os círculos restritos do poder, ao passar a envolver a generalidade dos membros instruídos das diferentes comunidades, chamados tanto a eleger os seus representantes quanto a seguir a evolução dos acontecimentos nacionais e internacionais.

As novas ágoras em que as sociedades contemporâneas se transformam ficaram a dever-se, no essencial, à imprensa, pois a definição e a instituição do espaço público contemporâneo foram proporcionadas pela mediação expedita e massiva das notí-

\footnotetext{
Seminário Livre de História das ideias, Centro de História da Cultura da Faculdade de Ciências Sociais e Humanas da Universidade Nova de Lisboa.
} 
cias, dos artigos e das controvérsias com que as publicações periódicas ocuparam as suas páginas.

Viveu-se, em consequência, um tempo de palavra impressa: a era em que o hábito de leitura dos periódicos, em casa, nos cafés, nos clubes, nas colectividades, fez nascer a opinião pública e alimentou com desvelo as diferentes constelações de afinidades em que os cidadãos reconheceram filiação, ao mesmo tempo que encontravam, entre si, linhas de fractura e de oposição.

A generalização do debate público democrático, resultado directo da actividade da imprensa periódica e consequência indirecta do papel que a escolarização havia conquistado na vida social, nomeadamente nos meios urbanos, revigorou as expectativas, mais ou menos promissoras, atribuídas às doutrinas e aos imaginários em confronto, ao permitir que a racionalidade categórica que se lhes imputava passasse a surgir associada ao efeito social e político resultante da sua propagação e da sua presença efectiva na comunidade.

Os homens do pensamento, das letras, das artes e das ciências ganharam, em consequência, uma autoridade que superava o domínio próprio da actividade com que cada um tinha alcançado reputação, pois as circunstâncias converteram-nos, genericamente, em figuras de proa da vida colectiva.

A cidade passou a respirar a atmosfera peculiar que a aproximação estreita entre cultura e política lhe proporcionava.

Ao sentirem-se vinculados ao dever que obrigaria os representantes do saber a participar no tecer do destino comum, os homens de cultura viram-se impelidos para a promoção, intramuros, dos avanços civilizacionais; para a divulgação de novas doutrinas regeneradoras, de índole social, política, pedagógica, entre outras; para a definição de causas e de querelas inerentes aos valores que encarnavam; para a crítica metódica de situações tidas por inaceitáveis e para o esclarecimento tempestivo do fluir dos acontecimentos.

A publicação em periódicos passou a prevalecer sobre a edição em livro, pois as constelações de artigos apresentavam-se mais adequadas, quer à formulação e divulgação de um pensamento actuante, quer à constituição e ao sustento metódicos de correntes de opinião, quer, por fim, ao confronto, frequentemente polémico, acerca do significado de teses e de factos.

As revistas revelaram-se, então, uma modalidade de imprensa particularmente adequada à persecução de desígnios compartilhados: as grandes figuras da cultura dirigiram-nas, os títulos multiplicaram-se, as orientações programáticas diversificaram-se, 
os leitores adquiriram o hábito de acompanhar fielmente os semanários, os quinzenários e os mensários da sua simpatia.

A compreensão da história cultural e política contemporânea, ao longo de alguns dos seus períodos mais ricos e intensos, obriga, pois, a atender às condições relativamente particulares em que decorreu, que não resultaram de limitações cerceadoras, mas, pelo contrário, das expectativas sociais elevadas que acompanharam os agentes culturais.

A figura do autor afastou-se então do seu estatuto de simples criador de objectos culturais, ao mesmo tempo que as modalidades de produção e de publicitação se distanciaram dos seus padrões tradicionais.

Foi a percepção de que a peculiaridade da vida cultural no período áureo da imprensa obriga a uma abordagem historiográfica própria, distinta dos procedimentos epistemológicos aplicados a épocas em que os géneros cultivados se confinam às convenções disciplinares, que levou o Seminário Livre de História das Ideias a dirigir os seus trabalhos, num primeiro momento, para a temática da missão cívica dos homens de cultura, com a edição de um conjunto de estudos sobre Dreyfus e a responsabilidade intelectual (Lisboa, Cadernos de Cultura 2, Centro de História da Cultura, 1999); a considerar, de seguida, o percurso dos movimentos cívico-culturais dos decénios iniciais do século XX, com a publicação de Revistas, ideias e doutrinas. Leituras do pensamento contemporâneo (Lisboa, Livros Horizonte, 2003); e a enveredar, por último, pela reedição electrónica - com estudo introdutório, índices e documentação conexa - de alguns dos títulos mais representativos das revistas de ideias e cultura da última centúria, como Alma Nacional, Estudos Sociais, Portugália e O Tempo e o Modo, nas suas duas séries (seguidos, brevemente, por A Águia, Atlântida, Nação Portuguesa, Revista de Educação Geral e Técnica, Estudos, Raiz e Utopia, Suplemento Literário e llustrado A Batalha, cujos trabalhos preparatórios de edição, nomeadamente os analíticos, se encontram concluídos).

Os estudos, e restantes textos, publicados no presente número de Cultura. Revista de História e Teoria das Ideias relevam, igualmente, do trabalho desenvolvido a propósito dos periódicos em que o pensamento e a sensibilidade portugueses recentes conheceram elaboração.

Os artigos seguem três vertentes distintas, embora, entre si, complementares: depoimentos a propósito de revistas, estudos monográficos acerca de títulos salientes, reflexão acerca da natureza e do papel destes periódicos, bem como sobre as questões de âmbito científico colocadas a propósito da sua republicação, em formato electrónico, na actualidade. 
O testemunho do Dr. Mário Soares consiste na transcrição das palavras com que evocou o papel de algumas das revistas principais da história portuguesa recente, bem como a sua condição de articulista, por ocasião da apresentação pública, na Faculdade de Ciências Sociais e Humanas, da reedição de Alma Nacional. Já o depoimento assinado por Adelino Cardoso traça o panorama das revistas filosóficas nas últimas décadas, a partir da recordação do papel activo por si desempenhado na criação e na produção de uma parte importante das publicações que revelaram o incremento que os estudos filosóficos conheceram após a criação dos cursos de especialização.

A maioria dos estudos agora publicados incide, porém, sobre revistas do tempo da I República, não por intuito comemorativo, mas por a nova pátria dos cidadãos ter encontrado nas páginas dos periódicos de ideias um lugar de eleição para a discussão plural e muito intensa entre as diferentes doutrinas do bem comum que a atravessaram. Estas nortearam, supostamente, tanto aqueles que fizeram a "velha" República, quanto os defensores do renascimento nacional ou da nova "grei", bem como todos os que se opuseram ao regime saído do 5 de Outubro, fossem católicos e corporativistas, integralistas e legitimistas, libertários e anarco-sindicalistas.

O projecto de uma comunidade cultural luso-brasileira, com claro significado político, propugnado pela revista Atlântida, editada durante a I Grande Guerra e nos anos que se lhe seguiram, sob a direcção de João do Rio e de João de Barros e com subvenção de governos republicanos portugueses e brasileiros, é objecto de dois estudos, de Lucia Maria Paschoal Guimarães e de Zília Osório de Castro, que, a seu modo, replicam, embora no plano da investigação e na actualidade, o pressuposto da existência de perspectivas e interesses complementares entre aqueles que a história e a cultura uniram.

Os artigos de Maria João Cabrita, José Manuel Cordeiro, Paulo Dias Oliveira, Pedro Silva e Adelaide Vieira Machado - centrados, respectivamente, na colaboração de Ferreira de Castro no Suplemento Literário e Ilustrado de A Batalha, nas edições da primeira série da revista Nação Portuguesa, nos números publicados na segunda série deste título integralista, em Estudos Sociais, editado pelo Centro Académico da Democracia Cristã, em A Águia, publicação associada ao movimento Renascença Portuguesa - constituem estudos desenvolvidos dos periódicos que serviram de órgãos a quatro dos principais movimentos político-culturais da década e meia republicana, além de as suas teses terem prevalecido, nomeadamente no caso da segunda e da terceira publicações referidas, muito para além da vitória da Revolução Nacional, já que os alicerces da cultura política nacionalista e de inspiração católica do Estado Novo lhes são devidos. 
Os estudos de Sandra Ataíde Lobo, acerca de Índia Nova, expressão da elite republicana goesa nos anos incertos da Ditadura Militar, e de Cristina Montalvão Sarmento, sobre a Revista Internacional de Língua Portuguesa, publicada pela Associação das Universidades de Língua Portuguesa, já no final do século XX, dão conta igualmente de duas investigações focadas em títulos emblemáticos, embora de âmbito mais circunscrito.

Já o artigo de Teresa Salvador reveste-se de um alcance geral no domínio das publicações periódicas femininas, ao proceder a análise reflexiva e panorâmica acerca do seu valor, da sua natureza e do seu poder.

As revistas enquanto modalidade editorial de produção e de divulgação do pensamento e da cultura são o objecto de estudo de Luís Andrade, enquanto os pressupostos e as opções que têm presidido à reedição electrónica de revistas, por parte do Seminário Livre de História das Ideias, em colaboração com a Fundação Mário Soares e com a Biblioteca Nacional de Portugal, são apreciados no artigo de que Pedro Lisboa é o autor.

O Projecto Edição de Revistas de Ideias e Cultura do Século XX é financiado pela Fundação para a Ciência e a Tecnologia e pelo Programa Operacional Ciência e Inovação 2010, comparticipado pelo fundo comunitário Feder.

Estamos em crer que o conjunto dos contributos para o conhecimento das revistas de ideias e de cultura portuguesas do século XX agora publicados beneficia quer do afastamento relativamente ao rasto de memória - desde logo, de memória própria e de memória alheia, que muitas destas publicações suscitaram ao longo de décadas, 0 que revela, só por si, a pregnância ideológica que as caracterizou -, quer do desprendimento que guarda relativamente à aproximação da vida cultural a partir do seu viés literário, abordagem inteiramente pertinente e com mérito próprio, mas que, face à complexidade e à diversidade do conjunto das matérias em discussão, se revela muitas vezes parcelar e oblíqua. 